\title{
Atrial Natriuretic Peptide, Arginine Vasopressin Peptide and Cortisol Serum Levels in Opiate-Dependent Patients
}

\author{
Alexander Glahn ${ }^{a}$ Annemarie Heberlein ${ }^{a}$ Kenneth M. Dürsteler-MacFarland ${ }^{\mathrm{e}}$ \\ Bernd Lenz $^{b}$ Helge Frieling ${ }^{a}$ Michael Gröschl ${ }^{c}$ Gerhard A. Wiesbeck ${ }^{e}$ \\ Johannes Kornhuber $^{b}$ Dominikus Bönsch ${ }^{d}$ Stefan Bleich ${ }^{a}$ \\ Thomas Hillemacher ${ }^{a}$ \\ ${ }^{a}$ Center for Addiction Research (CARe), Department of Psychiatry, Social Psychiatry and Psychotherapy, Hannover \\ Medical School, Hannover, Departments of b Psychiatry and Psychotherapy, and 'Pediatrics, University Hospital

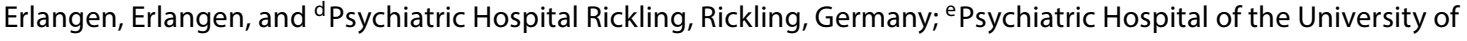 \\ Basel, Division of Substance Use Disorders, Basel, Switzerland
}

\section{Key Words}

Atrial natriuretic peptide Arginine vasopressin peptide .

Cortisol · Craving · Opiate dependence $\cdot$ Opiate

maintenance $\cdot$ Stress

\begin{abstract}
Preclinical studies suggest that chronic drug abuse profoundly alters stress-responsive systems. The best studied of the stress-responsive systems in humans is the hypothalamic-pituitary-adrenal (HPA) axis. Apart from cortisol, arginine vasopressin peptide (AVP), and atrial natriuretic peptide (ANP) are known to directly impact upon the HPA axis in addictive behavior. We investigated alterations in ANP, AVP and cortisol serum levels in opiate-dependent patients who received diacetylmorphine treatment within a structured opiate maintenance program. ANP serum levels were significantly increased in opiate-dependent patients as compared to healthy controls, whereas AVP and cortisol serum levels
\end{abstract}

were reduced. The ANP, AVP and cortisol serum levels were not significantly associated with the psychometric dimensions of heroin craving. In conclusion, chronic drug abuse profoundly alters stress-responsive systems like the HPA axis. Alterations of AVP, ANP and cortisol appear to constitute an important component in the neurobiology of opiate-dependent patients.

Copyright $\odot 2013$ S. Karger AG, Basel

\section{Introduction}

Heroin dependence is a chronic relapsing brain disorder that is characterized by a broader concept including compulsions and obsessions to use heroin $[1,2]$. This is usually driven by heroin craving resulting from drugconditioned stimuli and stress. Craving is a multidimensional phenomenon, consisting of cognitive, emotional and neurobiological aspects and can manifest itself when

\section{KARGER}

Fax +4161306 1234

E-Mail karger@karger.com

www.karger.com (c) 2013 S. Karger AG, Basel

0302-282X/13/0672-0111\$38.00/0

Accessible online at:

www.karger.com/nps
Alexander Glahn, MD

Center for Addiction Research (CARe), Department of Psychiatry

Social Psychiatry and Psychotherapy, Hannover Medical School

Carl-Neuberg-Strasse 1, DE-30625 Hannover (Germany)

E-Mail glahn.alexander@mh-hannover.de 
triggered by drug-related cues but also as a general desire or even obsession to use substances [2]. A growing body of evidence suggests that vasopressinergic neuronal activity in the amygdala and hypothalamus constitutes an important component in the neurobiology of stress-related behavior in rodent models [3]. Zhou et al. [4] explored the role of arginine vasopressin peptide (AVP) in drug addiction by examining AVP gene expression in the rat amygdala and hypothalamus and found that amygdala AVP mRNA levels were increased during early heroin withdrawal only. Moreover, stress has long been recognized as a major factor contributing to the development and perpetuation of drug addiction [4]. For example, psychological stress elevates drug craving [5] and stress-induced hypothalamic-pituitary-adrenal (HPA) axis responses predict amounts of subsequent drug abuse. Drugs of abuse themselves, and withdrawal from such drugs, can act as stressors promoting persistent and compulsive drug abuse [4]. During the 1980s, evidence emerged implicating AVP in the motivational properties of heroin and cocaine. Systemic administrations of desglycinamide-Arg8-vasopressin decreased heroin self-administration [6]. Alterations of volume-regulating hormones have also been described in other psychiatric conditions, including alcohol dependence [7]. Recent studies have reported alterations in volume-regulating hormones in early abstinent patients with alcohol dependence. These alterations seem to be linked with craving and other psychological dimensions occurring in the course of the disease [8]. Among these hormones, AVP and atrial natriuretic peptide (ANP) as well as cortisol have received the most extensive interest as they are known to exert direct effects on central nervous system endocrinological pathways [9]. Vasopressin is known to enhance memory function and has been proposed to have anxiogenic effects [10], whereas ANP is known to have strong anxiolytic effects and to exert a specific action on different levels of the HPA axis [11]. In particular, ANP inhibits the secretion of corticotrophin-releasing hormone, adrenocorticotrophic hormone and cortisol [12]. Gerber et al. [13] described acute effects of diacetylmorphine (DAM) on HPA axis activity and craving. In this study, DAM administration induced a significant decrease in plasma adrenocorticotrophic hormone, serum cortisol and saliva cortisol, as well as in craving over time. The suppressive effects of opioids in general on stress hormone secretion and subjective craving has already been shown [14-16].

Based on these preclinical study results, it was our goal to examine the effects of DAM on ANP, AVP and cortisol serum levels in opiate-dependent patients. Furthermore, we investigated a putative association between these serum levels and a craving for opiates.

\section{Materials and Methods}

Twenty-three opiate-dependent male patients (mean \pm SD: age, $41.83 \pm 6.77$ years; duration of opiate dependence, $21.48 \pm$ 6.25 years; dose of DAM injected, $334.35 \pm 128.09 \mathrm{mg} /$ day) were included in the study recruited from the Heroin Prescription Centre of the Psychiatric Hospital of the University of Basel, Switzerland. All patients fulfilled DSM-IV criteria for opiate dependence and had participated in a DAM maintenance program for at least 2 months before participating in the study. All patients received individual doses of DAM twice a day. Since the HPA axis is also widely discussed in affective disorders $[17,18]$, patients suffering from axis I diagnoses other than opiate dependence and substance abuse were excluded from the study, as were patients showing positive breath alcohol concentrations. The study adhered to the declaration of Helsinki (revised in 2008) and was approved by the Ethics Committee of the University of Basel. All patients gave written informed consent.

The ANP, AVP, and cortisol serum levels were investigated directly before and $45 \mathrm{~min}$ after regular injection of DAM in the morning (time since last injection was $16 \mathrm{~h}$ ) and in the afternoon ( $7 \mathrm{~h}$ after the morning injection). The serum levels of the patients investigated directly before and $45 \mathrm{~min}$ after regular injection of DAM in the morning were obtained fasting. The blood samples taken in the afternoon were not obtained fasting. The ANP, AVP and the cortisol serum levels obtained in the opiate-dependent patients were compared to the fasting serum levels of healthy controls [ 28 healthy male controls: age (mean \pm SD), $27.1 \pm 3.49$ years]. Controls were screened for alcohol abuse using the Alcohol Use Disorder Identification Test-Alcohol Consumption questions [19]; for axis I diagnoses, a structured interview was used. A score below 4 points in the Alcohol Use Disorder Identification TestAlcohol Consumption was required for subjects to be included in the control group. Controls were negative for axis I diagnoses according to DSM-IV.

Craving for heroin was measured psychometrically using the Heroin Craving Questionnaire [20]. The 45-item Heroin Craving Questionnaire measures positive (desire to use, intention to use, anticipation of positive outcome) and negative (relief from withdrawal and dysphoria, lack of control over use) factors of craving on 5 theory-derived subscales. Craving for heroin, methadone, alcohol and cocaine was additionally measured using $100-\mathrm{mm}$ visual analogue scales.

AVP, ANP and cortisol plasma levels were assessed using the DuoSet ELISA Development System (vasopressin: EIA-3122 DSL/ Beckman Coulter; ANP: USCN Life Science Inc. Wuhan; cortisol: Beckman Coulter DSL-10-2000). All assays were performed according to the manufacturer's recommendations.

\section{Statistical Analyses}

As none of the measured serum levels were found to be normally distributed according to the Kolmogorov-Smirnov test, we used nonparametric tests such as the Mann-Whitney test for 
comparing patient serum levels of the defined periods with the data of controls and Spearman's correlation for statistical analysis. The Wilcoxon test was used to evaluate differences in levels between the defined measurements within the same group. The 2 -tailed significance level was set at $\mathrm{p}<0.05$. The data were analyzed using PASW Statistics 18.0 (SPSS Inc., Chicago, Ill., USA) and Graph Pad Prism ${ }^{\text {TM }}$ 5.0 (Graph Pad Software Inc., San Diego, Calif., USA).

\section{Results}

The AVP, ANP and cortisol serum levels were not associated with the duration of opiate dependence, age, or dose of DAM injected (data not shown).

We found significantly increased ANP serum levels in the opiate-dependent patients as compared to the healthy controls 45 min after regular injection of DAM (MannWhitney test: $\mathrm{Z}=-1.529, \mathrm{p}=0.007$ ) in the morning (time frame of last injection $16 \mathrm{~h})$, and in the afternoon $(7 \mathrm{~h}$ after the morning injection) directly before $(Z=-2.628$, $\mathrm{p}=0.009)$ and $45 \mathrm{~min}$ after regular injection $(\mathrm{Z}=-3.040$, $\mathrm{p}=0.002)$ of DAM, whereas the cortisol levels at these points of measurement were found to be significantly suppressed $(Z=-1.328, p=0.184 ; Z=-2.411, p=0.016$; $\mathrm{Z}=-4.967, \mathrm{p}=0.000 ; \mathrm{Z}=-5.222, \mathrm{p}=0.000$ ). AVP levels were reduced over the whole study period compared to controls $(\mathrm{Z}=-3.029, \mathrm{p}=0.002 ; \mathrm{Z}=-2.233, \mathrm{p}=0.001 ; \mathrm{Z}=$ $-3.362, p=0.001 ; Z=-3.048 p=0.002)$. The Wilcoxon test for comparison of the ANP and AVP levels before and after injection of the regular dose of DAM showed no significant differences in the morning or in the afternoon, whereas the cortisol serum levels changed significantly $(\mathrm{Z}=-3.010, \mathrm{p}=0.003 ; \mathrm{Z}=-2.343, \mathrm{p}=0.019)$. The ANP, AVP and cortisol serum levels were not significantly associated with the psychometric dimensions of heroin craving. Moreover, we found no significant correlation of ANP, AVP and cortisol serum levels with the psychometric dimensions of alcohol, methadone and cocaine craving (data not shown).

\section{Discussion}

To our knowledge, this is the first study investigating serum levels of ANP, AVP and cortisol in opiate-dependent patients. In this pilot study, we found increased serum levels of ANP and reduced serum levels of AVP and cortisol in opiate-dependent patients during opiate maintenance. The comparison of the cortisol serum levels before and after injection of the regular dose of

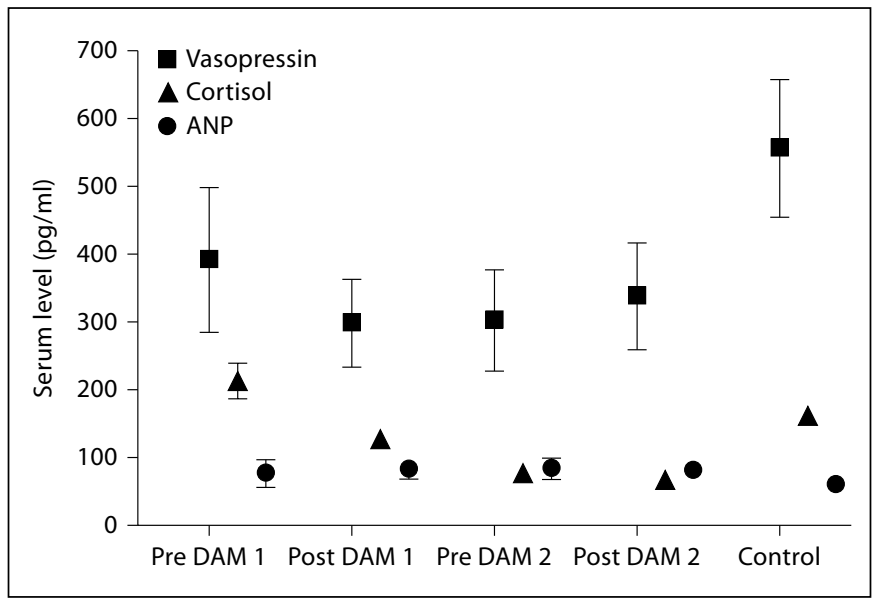

Fig. 1. ANP, AVP and cortisol serum levels (pg/ml) before and after the scheduled injection of DAM in opiate-dependent patients as compared to healthy controls. Serum levels were investigated directly before and $45 \mathrm{~min}$ after regular injection of DAM in the morning (time frame of last injection $16 \mathrm{~h}$ ) and in the afternoon $7 \mathrm{~h}$ after the morning injection.

DAM showed significant decreases from pre- to postinjection (fig. 1).

We found no significant association between the serum levels before the regular morning injection of DAM and craving for heroin. The serum levels were not associated with psychometric dimensions of heroin craving.

Zhou et al. [4] have shown that drugs of abuse on a chronic basis profoundly alter stress-responsive systems. Alterations in the expression of specific genes involved in stress responsivity and resultant changes in hormone levels have been documented to occur after chronic intermittent exposure to heroin, morphine, cocaine and alcohol $[4,7]$.

The HPA axis is undoubtedly the best studied of the stress-responsive systems in humans. A recent study examined acute effects of DAM on HPA axis function and heroin craving in a controlled experimental setting, demonstrating that DAM suppressed HPA axis activity [13]. As shown in alcohol-dependent patients, ANP and AVP, which indirectly regulate the HPA system, may also modulate the intensity of craving or the intensity of withdrawal symptoms [7]. Zhou et al. [4] showed that AVP mRNA levels in the amygdala were not altered during chronic heroin exposure in rats. However, they found that early spontaneous withdrawal (12 h) was associated with increases in amygdala AVP mRNA levels. This effect was tissue-specific, as they observed no effect of early heroin withdrawal in the hypothalamus, where AVP mRNA is 
constitutively expressed. In our study, AVP plasma levels of the patients were decreased, whereas ANP plasma levels increased compared to healthy controls. Vasopressin is known to enhance memory function and is proposed to have anxiogenic effects [10]. ANP is known to have strong anxiolytic effects and like vasopressin, to exert specific alterations on different levels of the HPA axis [11, 21]. Recent studies have reported a dysregulation of ANP plasma levels in the pathophysiology of different psychiatric conditions including depression, eating disorders and alcohol withdrawal $[8,22,23]$. The decreased cortisol levels after DAM injection in our study are in line with the results of Walter et al. [24] who found a suppressing effect of DAM on cortisol during stress situations which underscores the acute pharmacological potency of DAM on cortisol response in opioid maintenance treatment. ANP and cortisol serum levels were altered conversely, which could be due to the inhibitory effect of ANP on cortisol [12]. The missing significant changes in ANP and AVP plasma levels before and after injection of the regular dose of DAM in the morning and the afternoon could be explained by long-term effects of ANP and AVP as well as by the long-term and multiple substance abuse of this heterogeneous comorbid patient population. Furthermore, the sample size was small. This does not allow sound subgroup comparisons and indicates that largescale studies, which would permit to control various risk factors and assess their impact on ANP, AVP and cortisol serum levels and craving, are needed. Furthermore, the results may not accurately reflect the effect of ANP, AVP and cortisol on opiate dependence and susceptibility in the general population because of the small control group; in addition, the patients were recruited from a special clinic that is prone to volunteer bias. Moreover, the data were collected only at 4 time points during a single 1-day period of DAM maintenance. Further studies are needed to examine patients and controls at various time points over longer periods of time. The ANP, AVP and cortisol serum levels were not significantly associated with the psychometric dimensions of heroin craving. It could be argued that the patients were not really craving opiates since they received DAM for their opiate dependence in sufficient doses and at relatively regular times of the day. Thus, the patients might not have exhibited greater variations in craving. Since the HPA axis is also widely discussed in affective disorders [17, 18], the psychopathology of the patients at the time of blood sampling should be assessed as exact as possible in future studies.

In summary, chronic drug abuse profoundly alters stress-responsive systems like the HPA axis. Alterations of AVP, ANP and cortisol seem to constitute an important component in the neurobiology of opiate-dependent patients, even though the neurobiological mechanisms are not well understood. On this basis, further investigations focusing on hormonal long-term alterations in opiate-dependent patients are needed.

\section{References}

1 Koob GF: The neurobiology of addiction: a neuroadaptational view relevant for diagnosis. Addiction 2006;101(suppl 1):23-30.

2 Franken IH, Hendriksa VM, van den Brink W: Initial validation of two opiate craving questionnaires the obsessive compulsive drug use scale and the desires for drug questionnaire. Addict Behav 2002;27:675-685.

3 Wigger A, Sanchez MM, Mathys KC, Ebner K, Frank E, Liu D, Kresse A, Neumann ID, Holsboer F, Plotsky PM, Landgraf R: Alterations in central neuropeptide expression, release, and receptor binding in rats bred for high anxiety: critical role of vasopressin. Neuropsychopharmacology 2004;29:1-14.

4 Zhou Y, Leri F, Cummins E, Hoeschele M, Kreek MJ: Involvement of arginine vasopressin and V1b receptor in heroin withdrawal and heroin seeking precipitated by stress and by heroin. Neuropsychopharmacology 2008; 33:226-236.

5 Sinha R, Garcia M, Paliwal P, Kreek MJ, Rounsaville BJ: Stress-induced cocaine craving and hypothalamic-pituitary-adrenal re- sponses are predictive of cocaine relapse outcomes. Arch Gen Psychiatry 1999;63:324-331.

6 van Ree JM, Burbach-Bloemarts EM, Wallace M: Vasopressin neuropeptides and acquisition of heroin and cocaine self-administration in rats. Life Sci 1988;42:1091-1099.

7 Hillemacher T, Frieling H, Luber K, Yazici A, Muschler M, Lenz B, Wilhelm J, Kornhuber J, Bleich S: Epigenetic regulation and gene expression of vasopressin and atrial natriuretic peptide in alcohol withdrawal. Psychoneuroendocrinology 2009;34:555-560.

8 Kiefer F, Andersohn F, Jahn H, Wolf K, Raedler TJ, Wiedemann K: Involvement of plasma atrial natriuretic peptide in protracted alcohol withdrawal. Acta Psychiatr Scand 2002;105:65-70.

9 Döring WK, Herzenstiel MN, Krampe H, Jahn H, Pralle L, Sieg S, Wegerle E, Poser W, Ehrenreich $\mathrm{H}$ : Persistent alterations of vasopressin and $\mathrm{N}$-terminal proatrial natriuretic peptide plasma levels in long-term abstinent alcoholics. Alcohol Clin Exp Res 2003;27: 849-861.
10 Landgraf R: Neuropeptides in anxiety modulation. Handb Exp Pharmacol 2005;169: 335-369.

11 Ströhle A, Feller C, Strasburger CJ, Heinz A, Dimeno F: Anxiety modulation by the heart? Aerobic exercise and atrial natriuretic peptide. Psychoneuroendocrinology 2006;31: 1127-1130.

12 Antoni FA, Hunter EF, Lowry PJ, Noble JM, Seckl JR: Atriopeptin: an endogenous corticotropin-release inhibiting hormone. Endocrinology 1992;130:1753-1755.

13 Gerber H, Borgwardt SJ, Schmid O, Gerhard U, Joechle W, Riecher-Rössler A, Wiesbeck GA, Walter A: The impact of diacetylmorphine on hypothalamic-pituitary-adrenal axis activity and heroin craving in heroin dependence. Eur Addict Res 2012;18:116-123.

14 Bonfiglio JJ, Insa C, Refojo D, Holsboer F, Arzt E, Silberstein S: The corticotropin-releasing hormone network and the hypothalamic-pituitary-adrenal axis: molecular and cellular mechanisms involved. Neuroendocrinology 2011;94:12-20. 
15 Facchinetti F, Volpe A, Farci G, Petraglia F, Porro CA, Barbieri G, Cioni A, Balestrieri A, Genazzani AR: Hypothalamus-pituitaryadrenal axis of heroin addicts. Drug Alcohol Depend 1985;15:361-366.

16 Ho WKK, Wen HL, Fung KP, Ng YH, Au KK, Ma L: Comparison of plasma hormonal levels between heroin addicted and normal subjects. Clin Chim Acta 1977;75:415-419.

17 Holsboer F, Barden N: Antidepressants and HPA regulation. Endocr Rev 1996;17:187-205.

18 Holsboer F, Ising M: Stress hormone regulation: biological role and translation into therapy. Annu Rev Psychol 2010;61:81-109.
19 Saunders JB, Aasland OG, Babor TF, de la Fuente JR, Grant M: Development of the Alcohol Use Disorders Identification Test (AUDIT): WHO Collaborative Project on Early Detection of Persons with Harmful Alcohol Consumption. Addiction 1993;88:791-804.

20 Tiffany ST, Carter BL, Singleton EG: Challenges in the manipulation, assessment and interpretation of craving relevant variables. Addiction 2000;95:177-187.

21 Wiedemann K, Jahn H, Yassouridis A, Kellner M: Anxiolyticlike effects of atrial natriuretic peptide on cholecystokinin tetrapeptide-induced panic attacks: preliminary findings. Arch Gen Psychiatry 2001;58:371-377.
22 Ohashi M, Fujio N, Nawata H, Kato K, Matsubayashi S, Tamai $\mathrm{H}$, Matsuo $\mathrm{H}$, Ibayashi $\mathrm{H}$ : Human atrial natriuretic polypeptide in plasma of patients with anorexia nervosa. Horm Metab Res 1988;20:705-708.

23 Ströhle A, Holsboer F: Stress responsive neurohormones in depression and anxiety. Pharmacopsychiatry 2003;36:207-214.

24 Walter M, Wiesbeck GA, Degen B, Albrich J, Oppel M, Schulz A, Schächinger H, Dürsteler-MacFarland KM: Heroin reduces startle and cortisol response in opioid-maintained heroin-dependent patients. Addict Biol 2011; 16:145-151. 